\title{
The estimation of oxidative stress markers and apoptosis in right atrium auricles cardiomyocytes of patients undergoing surgical heart revascularisation with the use of warm blood cardioplegia
}

\author{
Rafal Nowicki ${ }^{1}$, Jolanta Saczko ${ }^{2}$, Julita Kulbacka ${ }^{2}$, Anna Choromanska ${ }^{2}$, \\ Malgorzata Dumanska ${ }^{3}$, Barbara Krajewska ${ }^{3}$, Malgorzata Daczewska ${ }^{4}$, \\ Andrzej Dumanski ${ }^{1}$, Wojciech Kustrzycki ${ }^{1}$
}

${ }^{1}$ Department of Cardiac Surgery, Medical University of Wroclaw, Poland

2Department of Medical Biochemistry, Medical University of Wroclaw, Poland

${ }^{3}$ Department of Histology and Embryology, Medical University of Wroclaw, Poland

${ }^{4}$ Department of General Zoology, Zoological Institute, University of Wroclaw, Poland

\begin{abstract}
Oxidative stress markers and apoptosis were estimated during elective surgical heart revascularization. Eight patients with good ejection fraction underwent coronary artery bypass grafting (CABG) with the use of warm blood cardioplegia. Two right atrium auricle biopsy specimens were collected before and after the operation. Specimens underwent immunocytochemical analysis of mitochondrial manganese superoxide dismutase (MnSOD) expression and apoptosis estimation by the TUNEL method. Ultrastructure analysis under electron microscope was made. Satisfactory results of the operation were obtained. After $\mathrm{CABG}$ the MnSOD expression increase in sections of auricles was observed through the increase of stain intensity and the percentage of cells with positive stain (from 30 to $80 \%$ ). The apoptotic cells percentage remained at approximately the same level. Under the electron microscope insignificant pathological changes were observed. On this basis one may assume that in the case of cardiosurgical procedures with short aorta cross-clamping time and low operation risk level the application of cardioplegia sufficiently prevents reactive oxygen forms (ROF) cytotoxic activity although it does not inhibit the expression of oxidative stress (OS) markers. In our opinion the method of examining right atrium sections is safe and provides results comparable with other publications. It may also be a voice in the discussion on new methods of heart protection during cardiac surgery procedures.
\end{abstract}

Key words: warm blood cardioplegia, oxidative stress, apoptosis, reactive oxygen forms, right atrium auricle

\section{Introduction}

Cardiac surgery on arrested heart with the application of extracorporeal circulation has been a safe method of treatment of numerous heart diseases, including coronary disease, for dozens of years. However, the cessation of coronary circulation involves the risk of postischemic reperfusion injury in the form of low output syndrome or the irreversible heart infarct (necrosis) [14]. To minimise the consequences of the myocardial

Correspondence: R. Nowicki, Dept. of Cardiac Surgery, Medical University of Wroclaw, Curie-Sklodowskiej Str. 66, 50-369 Wroclaw, Poland; tel.: (+4871) 7842221,

e-mail: ravnov@wp.pl ischemia during the surgery, a number of protection methods have been introduced, the most important one is the application of cardioplegia [5,6].

The heart is an organ characterised by exceptional aerobic metabolism which is extremely sensitive to ischemia: the reserve of ATP after aorta cross-clamping (cessation of coronary perfusion) is sufficient for only about a dozen heart systoles. As a result of coronary circulation cessation the oxidative phosphorylation cessation takes place, ATP level decreases, there is also anaerobic metabolites retention as well as free radicals and peroxide production.

The production of free radicals and oxidative stress that induces myocardial injuries in the ischemia/reperfusion period and the detection of oxidative stress after 
Table 1. Administration of warm blood cardioplegia according to the Calafiore protocol at $37^{\circ} \mathrm{C}$.

\begin{tabular}{|c|c|c|c|c|c|}
\hline $\begin{array}{c}\text { Portion } \\
\text { No. }\end{array}$ & $\begin{array}{c}\text { Time after } \\
\text { cross-clamping } \\
{[\mathrm{min}]}\end{array}$ & $\begin{array}{c}\text { Blood flow } \\
{[\mathrm{ml} / \mathrm{min}]}\end{array}$ & $\begin{array}{c}\mathrm{K}^{\prime} \text { solution flow } \\
{[\mathrm{ml} / \mathrm{h}\rceil}\end{array}$ & $\begin{array}{c}\text { Time of } \\
\text { application [min] }\end{array}$ & $\begin{array}{c}\text { Fntire dose of } \mathrm{K}^{\prime} \\
{[\mathrm{mF} / \mathrm{m}]}\end{array}$ \\
\hline 1 & 0 & 300 & bolus $2 \mathrm{ml}$, hen 150 & 2 & $18-20$ \\
\hline 2 & 15 & 200 & 120 & 2 & 20 \\
\hline 3 & 30 & 200 & 90 & 3 & 15 \\
\hline 4 & 45 & 200 & 60 & 4 & 6.3 \\
\hline 5 & 60 & 200 & 40 & 5 & 6.3 \\
\hline 6 & 75 & 200 & 40 & 5 \\
\hline
\end{tabular}

cardioplegic arrest are susceptible indicators of the efficacy of myocardial protection.

The toxic effect of reactive oxygen forms (ROF) during reperfusion is called oxidative stress (OS) and is related to the affinity of ROF to cell structures including lipids, proteins and nucleic acids. The oxidative reaction leads to cell malfunctions or even cells necrosis the consequence of which is organ insufficiency (the so called postoperative heart failure) $[7,8]$.

A conventionally used method of heart muscle protection is cardioplegia implemented to cardiac surgery as a standard in the $50 \mathrm{~s}$ of the previous century. Currently applied cardioplegic solutions are based on depolarizing abilities of potassium ions; however, research is conducted on low-potassium cardioplegia using sodium or magnesium ions $[5,9,11]$.

The protective effect of cardioplegia consists in quick cardiac arrest in diastole by cell membrane depolarisation and suppressing its electric activity. The additional decrease of myocardium oxygen demand during long operative procedures may be achieved by decreasing heart temperature thanks to: external cooling or cooled cardioplegic solution.

Currently used cardioplegic solutions are divided into two groups, the first one i.e., blood cardioplegia is based on patient's own blood and the other one the crystalloid cardioplegia, is an ion aqueous solution, its formula is similar to intracellular or extracellular fluid. Blood cardioplegia is obtained by mixing patient's blood with crystalloid cardioplegia by a ratio of $4: 1$ or $8: 1$, another method is adding potassium ions directly to blood (e.g.: the Calafiore protocol). Cardioplegia is administered to an aortic bulb, directly to coronary ostium (the so called antegrade) or to coronary sinus (the so called retrograde) at $37^{\circ} \mathrm{C}$ (normothermia) or below this temperature (hypothermia). At present there is no universal method of heart muscle protection. The selection of a particular method depends mainly on the preferences and experience of a particular centre or surgeon $[5,6]$.

There are numerous publications comparing blood and crystalloid cardioplegia [17-21]. Most of the authors claim that blood cardioplegia has better protective activity thanks to natural antioedematous, buffering and antioxidative properties. Thus it is recommended especially in the case of patients with decreased left ventricle ejection fraction or in the case of patients with indications for an urgent procedure, e.g. recent infarct or instable angina $[8,12,13]$. Regardless of this, in meta-analyses encompassing both longan short-term observations, no significant differences in mortality, morbidity and life quality after surgical heart revascularisation were found $[17,18]$. Moreover the supporters of crystalloid cardioplegia direct attention to lower costs and easier administration (often in one dose) which additionally reduces the time of aorta cross-clamping and myocardial ischemia.

In the Department of Cardiac Surgery of the Wroclaw Medical University we use mainly warm blood cardioplegia (in normotermia) in accordance with the Calafiore protocol (Table 1).

The aim of the study was to analyse oxidative stress indicators (MnSOD) in heart muscle samples taken form right atrium auricle of patients subjected to coronary artery bypass grafting (CABG). Additionally protective properties of applied warm blood cardioplegia were to be estimated in the aspect of apoptotic cells occurrence and changes in cardiomyocytes ultrastructure.

\section{Materials and methods}

Patient population. Prospective research encompassed 8 patients ( 1 woman and 7 men) at the age of 55-87, the average age was $69 \pm 8.56$, with stabile coronary disease (mean CCS was 2, Euro Logistic 2.65\%) and good initial left ventricle ejection fraction (EF), (Table 2). The present study followed the ethical guidelines of our department and informed consent was obtained from all patients.

Surgical technique. All patients underwent surgical coronary revascularisation $(\mathrm{CABG})$ by sternotomy using cardiopulmonary bypass (CPB). Warm blood cardioplegia protection was administered according to the Calafiore protocol in maximum three portions into the aortic bulb. Mean ejection fraction before the procedure was $60.62( \pm 9.5) \%$ for the whole group, mean time of the aorta cross-clamping was 29.5( \pm 9.46$)$ minutes. Approximately 
Table 2. Preoperative profile of patients.

\begin{tabular}{|c|c|}
\hline Number of patients & 8 \\
\hline Mean addilive LuroSCORL & $2.75 \pm 2.22$ \\
\hline Mcan logistic LuroSCORL & $2.65 \%$ \\
\hline Angina pectoris CCS & $2 \pm 0.7$ \\
\hline Sex (male/ female) & $7 / 1$ \\
\hline Age & $69 \pm 8.56$ \\
\hline Mean FF before operation [\%] & $60.62 \pm 9.5$ \\
\hline
\end{tabular}

$3( \pm 0.5)$ coronary artery bypass grafts were applied; each patient received one arterial by-pass (the left interior thoracic artery to the left anterior descending artery). Right atrium auricle biopsy specimens were collected from all patients: the first one when connecting cardiopulmonary bypass, the second one after reperfusion time, before decannulization. All specimens underwent immunohistochemical examination and ultrastructure analysis under an electron microscope.

Preparation of the paraffin sections. The auricle biopsy specimens were fixed in $10 \%$ neutral-buffered formalin solution, cut into $2 \times 2 \times 0.5 \mathrm{~mm}$ blocks and dehydrated in a series of graded ethanol solutions and set in paraffin. The paraffin blocks were cut at room temperature at $3.5 \mu \mathrm{M}$ thickness using a microtome (Leica RN 2255). The cut fragment was floated on distilled water, mounted on glass slide, then it was dried on a hot plate at $60^{\circ} \mathrm{C}$. The sections were deparaffinised in a xylene-ethanol series and also dehydrated in an ethanol-xylene series. The slides were used to immunohistochemical staining and TUNEL examination.

Apoptosis estimation by the TUNEL method. The percentage of apoptotic cells was estimated by the TUNEL method (ApopTag In situ Apoptosis Detection Kit - Peroxidase Oncor - Gaithersburg, USA) using the activity of terminal deoxynukleotidyl transferase (TdT). The method allows detecting six times more apoptotic cells than classical histological techniques because it detects late stages of apoptosis.

Immunocytochemical analysis of MnSOD expression. The sections underwent mitochondrial superoxide dismutase (MnSOD) expression test with the application of monoclonal antibodies against MnSOD (Santa Cruz, USA), in 1:100 solution. The assessment of reaction intensity was made with Olympus BH microscope (Olympus, Japan). The intensity of the immunohistochemical staining was evaluated in the following way: $(-)$ negative, $(+)$ poor, $(++)$ medium and $(+++)$ strong.

Ultrastructure analysis. Biopsies were fixed in cold 2,5-glutaraldehyde in $0.1 \mathrm{~mol} / \mathrm{L}$ cacodylate buffer $(\mathrm{pH} 7.3)$, postfixed in $1 \% \mathrm{OsO} 4$, dehydrated, and embedded in Epon. Thick sections (about $1 \mu \mathrm{m}$ ) were stained with toluidine blue and observed by light microscopy in order to select fields. Ultrathin sections were mounted on copper grids, stained with uranyl acetate and lead citrate, and examined under a Jem-100C (JEOL, Japan) electron microscope. Electron micrographs were taken systematically at $\times 5000$ magnification.

\section{Results}

The obtained, satisfactory results of the operation with acceptable morbidity and zero inter-hospital mortality
Table 3. Early operative results.

\begin{tabular}{|c|c|}
\hline Mean number of bypasses & $3 \pm 0.5$ \\
\hline Mean aorta cross-clamping time[min] & $29.5 \pm 9.46$ \\
\hline Mean CPB time [min] & $68.62 \pm 19.91$ \\
\hline Mcan intubation time $[\mathrm{h}\rfloor$ & $7.5 \pm 2.29$ \\
\hline Mean intensive care department stay [day] & $3.25 \pm 1.39$ \\
\hline Mcan Lil 4 day after procedure [\%] & $58.12 \pm 8.63$ \\
\hline $\begin{array}{l}\text { Mean CK-MB level } 24 \mathrm{~h} \text { after procedure } \\
{[\mathrm{ng} / \mathrm{mL} \text {.] }}\end{array}$ & $59.875 \pm 15.92$ \\
\hline IABP after opcration & $0(0 \%)$ \\
\hline Mean time of hospitalization [day] & 9.75 \\
\hline $\begin{array}{l}\text { Morbidity: } \\
\text { rethoracotomy due to bleeding } \\
\text { postoperative } \mathrm{Al} \text { : } \\
\text { perioperative infarct } \\
\text { calccholamins after operation } \\
\text { wound infection }\end{array}$ & $\begin{array}{c}1(12.5 \%) \\
3(37.5 \%) \\
0(0 \%) \\
2(25 \%) \\
0(0 \%)\end{array}$ \\
\hline Mortality: & $0(0 \%)$ \\
\hline
\end{tabular}

in the whole group are presented in Table 3. Taking into account the average number of implanted bypasses, namely $3 \pm 0.5$, we obtained short aorta crossclamping time $-29.5 \pm 9.46$ and short total time of the cardiopulmonary bypass (CPB). A slightly longer stay in the postoperative unit is related to the occurrence of atrial fibrillation (AF) in three operated patients, which makes over $1 / 3$ of the whole group, and to rethoracotomy resulting from bleeding in one of the patients. Two patients required inotropic support with catecholamine infusion during the first hours after the operation, it was discontinued within the first twenty four hours of hospitalisation in the postoperative unit. No low output syndrome was observed and none of the patients required intra aortic balloon pump (IABP). No perioperative heart infarct was diagnosed although the level of creatine kinase MB (CK-MB) slightly exceeded twice the upper limit. However, EF after the operation did not significantly differ from the initial value. All patients were released from hospital to await a place in the cardiological rehabilitation department.

\section{Immunocytochemical analysis of MnSOD expression}

After the surgery procedure the MnSOD expression increase in sections of right atrium auricles was observed through the increase of stain intensity and the percentage of cells with positive stain (from 30 to $80 \%$ ), (Table 4).

\section{TUNEL assay}



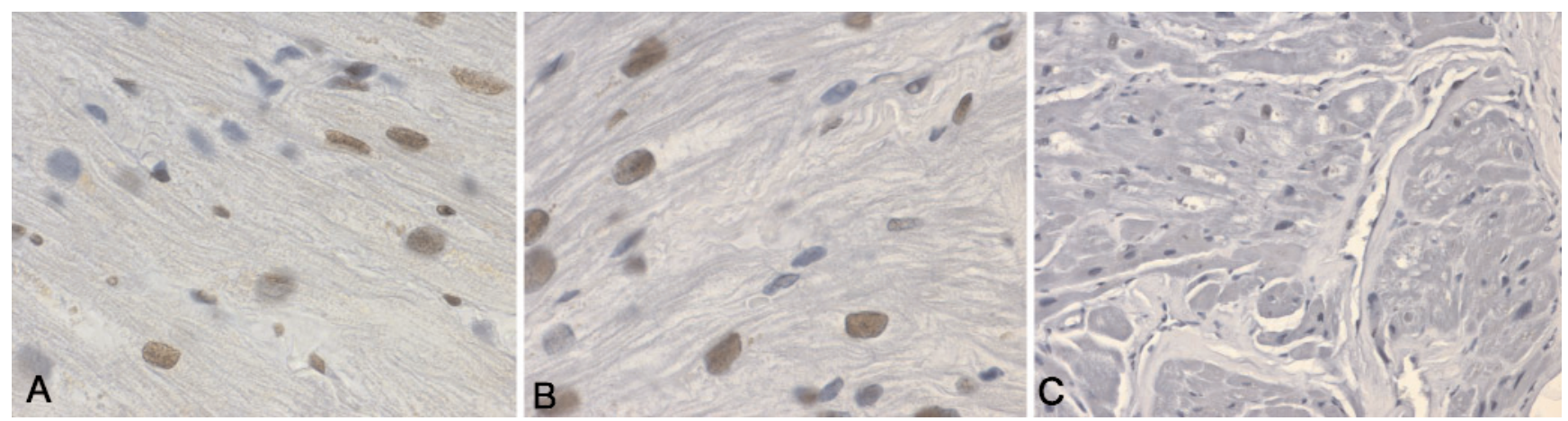

Fig. 1. (A) Apoptosis: before the surgery procedure (stain on paraffin section of a right atrium auricle, original magnification $\times 400$ ). (B) Apoptosis: after the surgery procedure (stain on paraffin section of a right atrium auricle, original magnification $\times 400$ ). (C) Apoptosis: control staining of the paraffin section of a right atrium auricle (original magnification $\times 200$ ).
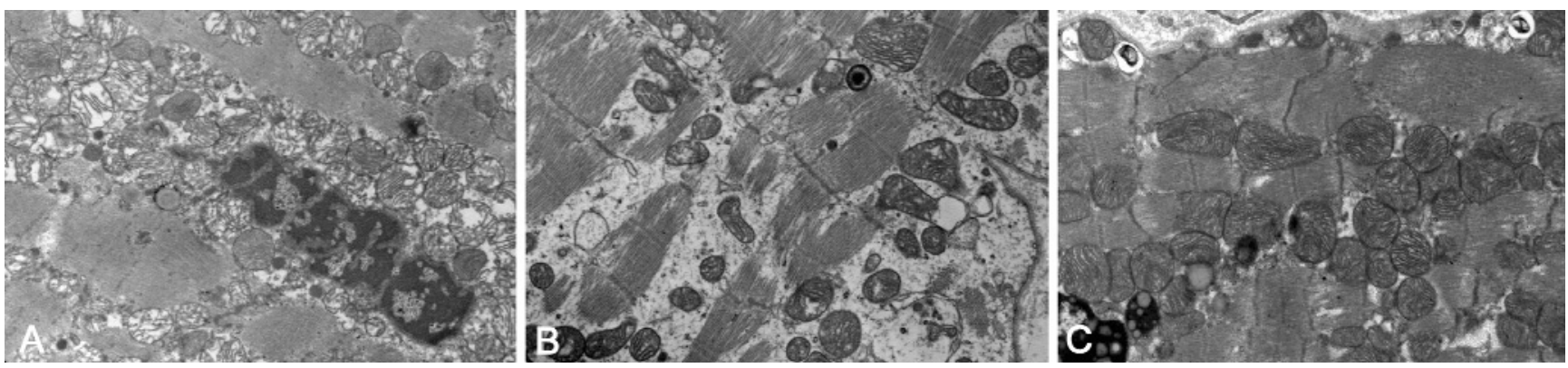

Fig. 2. (A) Ultrastructure of right atrium auricle after the cardiac surgery procedure. Visible cytoplasm vacuolization and translucent mitochondrial matrix. (B) Ultrastructure of right atrium auricle after the cardiac surgery procedure. Changed shape of mitochondria and visible abnormal filament organisation). (C) Ultrastructure of control right atrium auricle before the cardiac surgery procedure (original magnification $\times 5000$ ).

Table 4. MnSOD expression.

\begin{tabular}{|l|c|c|}
\hline & Before operation & $\Lambda$ fter operation \\
\hline Positive cells[\%] & 30 & 80 \\
\hline Stain intensity & $+/++$ & $++/+++$ \\
\hline
\end{tabular}

The apoptotic cells percentage remained at approximately the same level before and after the surgery procedure, (Fig. 1A, 1B, 1C).

\section{Ultrastructure analysis}

Under the electron microscope insignificant pathological changes at the level of mitochondria and cytoplasm of cardiomyocytes from the right atrium auricles were observed (Fig. 2A, 2B): cytoplasm vacuolization, translucent mitochondrial matrix, changed shape of mitochondria and abnormal filament organisation in comparison with the examination before the surgery procedure (Fig. 2C).

\section{Discussion}

In most cardiosurgical procedures, the heart is kept arrested for a substantial amount of time and subsequently undergoes reperfusion. The previous study documented the ROF formation upon reperfusion of ischemic myocardium with the consequent oxidative injury to cell function and structure $[1-4,15,16]$. The ROF production during the cardioplegic arrest is reduced by antioxidant enzymes $[10,24]$ which are one of OS markers. In available publications related to myocardial ischemia/reperfusion injury, some of the most common markers used for the assessment of OS are: glutathione (GSH) $[1,9,11]$, oxidized glutathione (GSSG) [1,7], manganese superoxide dismutase (MnSOD) [10,24], myeloperoxidase (MPO) [8] or thiobarbituric acid reactive substances (TBARS) like malondialdehyde (MDA) [8,11,14].

In our study we chose MnSOD, an enzyme which protects mitochondria from I/R injury and is the main antioxidant in all cells exposed to ROF. Thanks to the application of a sensitive and convenient method of direct determination of MnSOD using monoclonal antibodies, it was possible to observe a significant increase in its expression after reperfusion time, similar to 
Suzuki et al. [10] and Chan et al. [24] who had used animal hearts in their studies. OS markers are assessed in blood or myocardium tissue biopsies. In blood samples taken from coronary sinus Ferrari et al. determine GSH and GSSG [1], similar to Morishige et al. GSSG, MPO, MDA [8]. Tao et al. used blood from coronary sinus and peripheral vessels to estimate GSH [9], Milei et al. determine GSH and TBARS in blood samples taken from arterial line (CPB) and tissue biopsies of a left ventricle [11].

We decided to sample human right auricule intraoperatively because it is easy and safe to do that during cardiosurgical procedures. There are some authors who also obtained human right auricular samples, e.g. Abraham et al. presented an electromechanical dysfunction of myocardial specimens after remote exogenous ischemia-reperfusion [25], Canty et al. determined the activation of oxidative stress-responsive transcription factor in homogenized auricule tissue [27]. Atrial tissue was also used by Bukowska et al. for in vitro pacing experiments [28]. Wang et al. proved the cardioprotective effect of osteopontin against cardiac ischemia-reperfusion injury by measuring the SOD activity and MDA content in cells [29].

The TUNEL method detects single-stranded and double-stranded DNA breaks associated with apoptosis. Chronic ischemia related to coronary disease may cause the apoptosis of cardiomyocytes. In our study the apoptotic cells percentage remained at approximately the same level before and after the operation which proves the effectiveness of the applied warm blood cardioplegia. Similar to Gong et al., who estimated apoptosis in the atrium of patients with atrial septal defect, no TUNEL reactivity in the biopsy section from healthy control group [26] was observed. However Schmitt et al. found a small increase in the number of apoptopic cells after the operation, however, he used different cardioplegia (cold crystalloid) and the mean cardiac arrest time was twice as a long as in our research [30].

We also found less significant pathological changes in the cells under the electron microscope than Milei et al.[11]. Differences may be connected with the shorter aortic cross-clamp time and with the increased sensitivity of the left ventricle myocardium to ischemia compared to right atrium cardiomyocytes.

However, insignificant changes in right atrium auricles ultrastructure and a similar percentage of apoptotic cells before and after the surgery accompanied by good surgery results prove the effectiveness of the applied myocardial protection $[7,8,11,26]$. On this basis one may assume that in the case of cardiosurgical procedures with short aorta cross-clamping time (mean aorta cross-clamping time: $29.5 \mathrm{~min} .( \pm 9.46)$ in our material) as well as low operation risk level (mean logistic EuroSCORE: $2.65 \%$ in our material), the application of cardioplegia sufficiently prevents ROF cytotoxic activity although it does not inhibit the expression of OS markers [11].

The obtained results allowed to confirm the earlier observations related to the significance of OS during the reperfusion of cardioplegic arrested human heart $[4,10,12,14,15,26]$. More importantly the investigated material used in this work, i.e. a right atrium auricle, is relatively easily available and a sample can be taken safely and this is what makes the method worth recommending in clinical research.

\section{Conclusion}

In our opinion the method of examining right atrium sections is safe and provides results comparable with other publications. Summarizing, the antegrade perfusion of warm blood cardioplegia safely protects the human myocardium as cold blood cardioplegia. Furthermore, warm blood cardioplegia reduces the degree of myocardial oxidative stress during the reperfusion period after cardioplegic arrest. This consequence possibly will help in protection and resuscitation of the myocardium under environment of more severe or prolonged ischemia.The method may be developed to encompass the examination of substances enriching cardioplegia, it may also be a voice in the discussion on new methods of heart protection during cardiac surgery procedures.

\section{References}

[ 1] Ferrari R, Alfieri O, Curello S, et al. Occurrence of oxidative stress during reperfusion of human heart. Circulation. 1990;81:201-11.

[ 2] Ambrosio G, Tritto I. Reperfusion injury: experimental evidence and clinical implications. Am Heart J. 1999;138:69-75.

[ 3] Hansen PR. Myocardial reperfusion injury: experimental evidence and clinical relevance. Eur Heart J. 1995;16:734-740.

[ 4] Zweier JL, Talukder MA. The role of oxidants and free radicals in reperfusion injury. Cardiovasc Res. 2006;70(2):181190.

[5] Kuzemczak MM. Ochrona mięśnia sercowego przed niedokrwieniem w czasie chirurgicznej rewaskularyzacji. Chirurg.pl. Polski portal chirurgii i gastroenterologii. 2007. Available at: http://www.chirurg.pl/mod/archiwum/7012. Accessed September 14, 2009.

[ 6] Przybylski R. Techniki pomostowania aortalno-wieńcowego: Operacje na sercu zatrzymanym kardioplegią w krążeniu pozaustrojowym. In: Zembala M, ed. Chirurgia Naczyń Wieńcowych. Warszawa: PZWL; 2002:210-213

[7] Suzuki K, Murtuza B, Sammut IA, et al. Heat Shock Protein 72 Enhances Manganese Superoxide Dismutase Activity During Myocardial Ischemia-Reperfusion Injury, Associated With Mitochondrial Protection and Apoptosis Reduction. Circulation. 2002;106(I):270-276.

[ 8] Milei J, Forcada P, Fraga CG, et al. Relationship between oxidative stress, lipid peroxidation, and ultrastructural damage in patients with coronary artery disease undergoing cardioplegic arrest/reperfusion. Cardiovasc Res. 2007;73(4): 710-719. 
[ 9] Tao S, Calza G, Lerzo F, et al. Activation of the intracellular glutathione system by oxidative stress during cardiopulmonary bypass and myocardial perfusion. Perfusion. 1995; 10(1):45-50.

[10] Mezzetti A, Calafiore AM, Lapenna D, et al. Intermittent antegrade warm cardioplegia reduces oxidative stress and improves metabolism of the ischemic-reperfused human myocardium. $J$ Thorac Cardiovasc Surg. 1995;109(4):787-795.

[11] Noritsugu M, Tadashi T, Takashi Y. Michio K. Retrograde continuous warm blood cardioplegia reduces oxidative stress during coronary artery bypass grafting. Ann Thorac Cardiovasc Surg. 2002;8(1):31-37.

[12] Jenkins DP. Are patients with poor left ventricular function more prone to oxidative stress during cardiac surgery? Heart. 1998;79(3):219-219.

[13] De Vecchi E, Pala MG, Di Credico G, et al. Relation between left ventricular function and oxidative stress in patients undergoing bypass surgery. Heart. 1998;79(3):242-247.

[14] Toivonen HJ, Ahotupa M. Free radical reaction products and antioxidant capacity in arterial plasma during coronary artery bypass grafting. J Thorac Cardiovasc Surg.1994; 108(1):140147.

[15] Chambers DJ. Oxidative stress injury during cardiac surgery: How important is it? Cardiovasc Res. 2007;73:626-628.

[16] Semenza GL. Cellular and molecular dissection of reperfusion injury. ROS within and without. Circ Res. 2000;86:117-118.

[17] Jacob S, Kallikourdis A, Sellke F, Dunning J. Is blood cardioplegia superior to crystalloid cardioplegia? Interactive Cardio Vasc Thorac Surg. 2008;7:491-498.

[18] Guru V, Omura J, Alghamdi AA, Weisel R, Fremes S. Is blood superior to crystalloid cardioplegia? A meta-analysis of randomized clinical trials. Circulation. 2006;114(I):331-338.

[19] Ovrum E, Tangen G, Tollofsrud S, Oystese R, Ringdal MA, Istad R. Cold blood cardioplegia versus cold crystalloid cardioplegia: a prospective randomized study of 1440 patients undergoing coronary artery bypass grafting. J Thorac Cardiovasc Surg. 2004;128: 860-865.

[20] Rinne T, Pehkonen E, Kaukinen S, Tarkka M. Comparison of cardioprotection with crystalloid and blood cardioplegia in CABG patients. J Cardiothorac Vasc Anesth. 1993;7: 679-683.

[21] Martin TD, Craver JM, Gott JP. Prospective, randomized trial of retrograde warm blood cardioplegia: myocardial benefit and neurologic threat. Ann Thorac Surg. 1994;57:298.

[22] Torracca L, Pasini E, Curello S, et al. Continuous Versus Intermittent Warm Blood Cardioplegia: Functional and Energetics Changes. Ann Thorac Surg. 1996;62(4):1172-1179.

[23] Tossios P, Bloch W, Huebrer A, et al. N-acetylcysteine prevents reactive oxygen species-mediated myocardial stress in patients undergoing cardiac surgery: results of a randomized, placebo-controlled clinical trial. J Thorac Cardiovasc Surg. 2003;126:1513-1520.

[24] Chen Z, Siu B, Ho Y, et al. Overexpression of MnSOD protects against myocardial ischemia/reperfusion injury in transgenic Mice. J Mol Cell Cardiol. 1998;30:2281-2289.

[25] Abraham RB, Matza M, Marmur S, et al. Electromechanical impairment of human auricle and rat myocardial strip subjected to exogenous oxidative stress. Eur J Card Thorac Surg. 2003;23(1):66-73

[26] Gong J, Qian L, Kong X, et al. Cardiomyocyte apoptosis in the right auricle of patients with ostium secundum atrial septal defect diseases. Life Sci. 2007;80(12):1143-1151.

[27] Canty TG, Boyle EM, Farr A, Morgan EN, Verrier ED, Pohlman TH. Oxidative Stress Induces NF-KB Nuclear Translocation Without Degradation of IKB $\alpha$. Circulation. 1999;100(II):361-364.

[28] Bukowska A, Schild L, Keilhoff G, et al. Mitochondrial dysfunction and redox signaling in atrial tachyarrhythmia. Exp Biol Med. 2008;233:558-574.

[29] Wang Y, Chen B, Shen D, Xue S. Osteopontin protects against cardiac ischemia-reperfusion injury through late preconditioning. Heart Vessels. 2009;24(2):116-123.

[30] Schmitt JP, Schroeder J, Schunkert H, Birnbaum DE, Aebert $\mathrm{H}$ : Role of apoptosis in myocardial stunning after open heart surgery. Ann Thorac Surg. 2002;73:1229-35

Submitted: 17 September, 2009 Accepted after reviews: 11 March, 2010 